щелочной фосфатазы» в трофобласте хориальных ворсинок при различных видах воспаления последа.

Ключевые слова: плацентарная щелочная фосфатаза, воспаление последа.

\title{
ENZYMATIC ACTIVITY AND THE CONCENTRATION OF PLACENTAL ALKALINE PHOSPHATASE IN THE TROPHOBLAST OF CHORIAL VILLI OF THE PLACENTA IN CASE OF AFTERBIRTH INFLAMMATION (A HISTOCHEMICAL AND IMMUNOHISTOCHEMICAL INVESTIGATION)
}

\section{O.P. Shenderiuk}

Abstract. The author presents quantitative results of his own histochemical and immunohistochemical investigations of the enzymatic activity and the concentration of the specific placental protein «placental alkaline phosphatase» in the trophoblast of chorial villi with different varieties of afterbirth inflammation in this paper.

Key words: placental alkaline phosphatase, afterbirth inflammation.

Bukovinian State Medical University (Chernivtsi)

Рецензент - проф. О.А. Андрієць

Buk. Med. Herald. - 2013. - Vol. 17, № 1 (65). - P. 144-147

Надійшла до редакції 18.01.2013 року

(c) О.П. Шендерюк, 2013

УДК 616.24-002-085.281

О.А. Яковлева, Н.В. Щербенюк

\section{СТРУКТУРА НАЗНАЧЕНИЙ ЛЕКАРСТВЕННЫХ СРЕДСТВ ПРИ ЛЕЧЕНИИ НЕГОСПИТАЛЬНОЙ ПНЕВМОНИИ В СТАЦИОНАРАХ (В ТЕЧЕНИЕ 2011 ГОДА)}

Винницкий национальный медицинский университет им. Н.И. Пирогова

Резюме. С целью изучения реальной практики использования лекарственных средств при лечении негоспитальной пневмонии в стационарах г. Винницы был проведен ретроспективный анализ 760 медицинских карт стационарных больных. Результаты анализа показали, что для лечения негоспитальной пневмонии больные получали в среднем $10,18 \pm 0,13$ лекарственных препаратов. Антибактериальные препараты для системного применения получали все 760 пациентов, в среднем одному больному их назначалось $2,51 \pm 0,03$ (от 1 до

Введение. Негоспитальная пневмония (НП) относится к заболеваниям, имеющим важное медико-социальное значение, поскольку ее высокая распространенность и проблемы, связанные с диагностикой и лечением, определяют значительные экономические потери, которые государство несет в связи с этой патологией [6]. Накопленные к настоящему времени данные служат основой для периодического обновления национальных рекомендаций по ведению больных с НП. Основная цель клинических рекомендаций - улучшение диагностики и качества лечения больных с НП в амбулаторной практике и стационаре [5].

Применение стандартов и протоколов лечения в клинической фармакологии призвано регламентировать в некоторой степени субъективную составляющую клинического мышления врача. Однако этот аспект не может быть полностью устранен, с учетом различной психологии врачевания, опытом, стажем, уровнем знаний

(C) О.А. Яковлева, Н.В. Щербенюк, 2013
7). Достаточно часто применялись нестероидные противовоспалительные средства $(38,0 \%)$, сульфокамфокаин $(29,7 \%)$, биогенные стимуляторы $(23,2 \%)$, витамины $(8,6 \%)$. Полученные данные свидетельствуют о полипрагмазии и могут служить основой планирования комплекса мероприятий по совершенствованию фармакотерапии негоспитальных пневмоний.

Ключевые слова: негоспитальная пневмония, фармакоэпидемиология, фармакотерапия.

современных врачей. Поэтому тактика выбора необходимой фармакотерапии отражает ее многофакторную мозаику, которая должна объединить умения врача, свойства лекарственного препарата и индивидуальность пациента.

В какой мере эти три составляющие сочетаются в реальной врачебной практике и приводят к результатам эффективной фармакотерапии - можно изучить фармакоэпидемиологическим анализом.

Цель исследования. Получить объективные данные о практике применения лекарственных средств (ЛС) при лечении НП в стационарных условиях и оценить рациональность применяемых режимов терапии с точки зрения современных стандартов и клинической фармакологии.

Материал и методы. Для ретроспективного анализа отбирались медицинские карты стационарных больных, в возрасте от 16 до 65 лет, находившихся на лечении в пульмонологических отделениях г. Винницы с диагнозом НП с 01.01.11. по 
31.12.2011 г. В специально разработанных протоколах регистрировались паспортные данные, клинический диагноз, медицинский анамнез, назначение ЛС, режим дозирования антибактериальных препаратов (АБП) и путь введения, длительность лечения, нежелательные лекарственные реакции, указанные в медицинской карте стационарного больного. Эффективность терапии прослеживали по динамике клинических симптомов, данных рентгенологического и лабораторных исследований.

Результаты исследования и их обсуждение. Проанализированы данные 760 пациентов. Средний возраст больных 44,27 $\pm 0,49$ лет. Женщины составили 52,1 \%, мужчины - 47,9 \%. Средняя длительность госпитализации - 11,74 $\pm 0,11$ дней. Пациентов с диагнозом НП 3 клинической группы было 714 (93,9 \%), НП 4 кл. гр. - 46 (6,1 \%).

Наиболее частыми сопутствующими заболеваниями были: болезни органов кровообращения - у 337 больных (в 44,3\% случаев), заболевания органов дыхания - у 191 пациента (25,1 \% случаев), в структуре последних преобладали ХОЗЛ - 125 больных (16,4 \% случаев). Заболевания органов пищеварения встречались у 171 больного $(22,5 \%)$, органов мочеполовой системы - у 117 $(15,4 \%)$, эндокринной системы - у 88 (11,6 \%), костно-мышечной системы - у 23 (3,0 \%).

Результаты проведенного фармакоэпидемиологического анализа показали, что при лечении НП в стационаре больные получали от 4 до 28 (в среднем $10,18 \pm 0,13)$ лекарственных препаратов. Согласно АТС - классификации они распределялись следующим образом (табл. 1).

АБП для системного применения (J 01) получали все 760 пациентов (100 \%) (табл. 2), в среднем одному больному назначалось 2,51 $\pm 0,03$ АБП (от 1 до 7). Монотерапию получали только 36 больных (4,7\%), два АБП - 411 больных (54,1 $\%)$, три АБП - 232 (30,5\%), четыре АБП - 61 (8,0 $\%)$, пять АБП - 14 (1,9\%), шесть АБП - 4 $(0,05 \%)$, семь АБП - $2(0,3 \%)$.

Второй по частоте назначения группой ЛС были средства, действующие на респираторную систему - 736 больных (96,8 \%) (табл. 3).

Следующей по частоте назначения группой ЛС были средства, влияющие на систему крови и гемопоэз - 712 больных (93,7 \%) (табл. 4).

Такая высокая частота назначения данной группы ЛС связана с применением физиологического раствора хлорида натрия (В 05) в качестве растворителя для других ЛС, в т. ч. АБП.

Средства, влияющие на пищеварительную систему и метаболизм, получали 659 пациентов (86,7 \%) (табл. 5). Группа А 07 (Антидиарейные препараты; средства, применяемые для лечения инфекционно-воспалительных заболеваний кишечника) была представлена в основном пре- и пробиотиками - хилак, линекс, лактовит и др.; группа А 16 (Прочие средства, влияющие на пищеварительную систему и метаболические процессы) биогенными стимуляторами (плазмол, алоэ).
Достаточно часто применялись средства, влияющие на сердечно-сосудистую систему 459 больных (60,4 \%). Сульфокамфокаин, входящий в группу С 01, получали 226 больных (29,7 \%). Высокий процент назначений средств, действующих на нервную систему, обусловлен использованием лидокаина в качестве растворителя для АБП.

Обращает на себя внимание, что средства, влияющие на опорно-двигательный аппарат, получали 311 пациентов (40,9%). Причем группа противовоспалительных и противоревматических средств (М 01), среди которых наиболее часто диклофенак и нимесулид, применялась у 289 больных (38,0 \%).

Также обращает на себя внимание большая частота назначения иммуностимуляторов (L 03) эрбисол, циклоферон, нуклеинат, эхинацея и других у 119 пациентов (15,7 \%). Кортикостероиды для системного применения (Н 02) получали 76 больных (10,0\%), преимущественно больные с НП 4 кл. гр., с сопутствующими ХОЗЛ и бронхиальной астмой. Группа “другие” в основном представлена стерильной водой для инъекций.

Очевидно, что анализ фармакоэпидемиологических данных может быть полезен для оценки тактики фармакотерапии, применяемой врачами при НП. Прежде всего, должна быть осуществлена оценка этиопатогенетического лечения НП, где антибактериальные средства остаются первоочередными $[1,2]$. Можно считать уязвимой тактику применения трех и более АБП, которая способствует развитию резистентности микрофлоры в популяции $[2,3]$, что справедливо для 41,2 \% больных, получавших от трех АБП и более. Профилактическое применение противогрибковых ЛС не рекомендуется $[5,6]$, что можно считать ошибкой у 4,7 \% больных. При высокой частоте коморбидности НП с ХОЗЛ следует ожидать значительную частоту вирусно-бактериальной этиологии НП, что обусловливает назначение противовирусных ЛС.

Ситуация коморбидности вынуждает врачей применять у одного больного в среднем $10,18 \pm 0,13$ препаратов. Остается сомнительной такая высокая потребность в фармакотерапии даже в этих условиях, что только способствует полипрагмазии и расходу средств пациентов неадекватно целесообразности. К избыточной необоснованной терапии следует отнести также профилактическое применение антигистаминных ЛС, что по данным доказательной медицины противопоказано [5].

Профилактическое применение пре- и пробиотиков при антибиотикотерапии остается предметом дисскусий. Распространено мнение о необходимости их назначения параллельно с АБП для профилактики дисбактериоза [4]. Но эта тактика мало популярна в мировых стандартах, так как не соответствует индивидуальному генетическому биоценозу больных и представляет дополнитель- 


\section{Структура назначений ЛС различных фармакотерапевтических групп}

\begin{tabular}{|c|c|c|}
\hline \multirow{2}{*}{ Группа ЛС согласно АТС-классификации } & \multicolumn{2}{|c|}{ Количество больных, получавших ЛС } \\
\hline & абсолютное количество & $\%(n=760)$ \\
\hline $\begin{array}{c}\text { Код А: Средства, влияющие на пищеварительную } \\
\text { систему и метаболизм }\end{array}$ & 659 & 86,7 \\
\hline $\begin{array}{c}\text { Код В: Средства, влияющие на систему крови и } \\
\text { гемопоэз }\end{array}$ & 712 & 93,7 \\
\hline $\begin{array}{c}\text { Код С: Средства, влияющие на сердечно- } \\
\text { сосудистую систему }\end{array}$ & 459 & 60,4 \\
\hline $\begin{array}{c}\text { Код Н: Препараты гормонов для системного приме- } \\
\text { нения (кроме половых гормонов и инсулина) }\end{array}$ & 78 & 10,3 \\
\hline $\begin{array}{c}\text { Код J: Противомикробные средства для системного } \\
\text { применения }\end{array}$ & 760 & 100 \\
\hline $\begin{array}{c}\text { Код L: Антинеопластические и иммуномодулирую- } \\
\text { щие средства }\end{array}$ & 119 & 15,7 \\
\hline $\begin{array}{c}\text { Код М: Средства, влияющие на опорно- } \\
\text { двигательный аппарат }\end{array}$ & 311 & 40,9 \\
\hline Код N: Средства, действующие на нервную систему & 370 & 48,7 \\
\hline $\begin{array}{c}\text { Код R: Средства, действующие на респираторную } \\
\text { систему }\end{array}$ & 736 & 96,8 \\
\hline Другие & 206 & 27,0 \\
\hline
\end{tabular}

Таблица 2

Код Ј: Назначенные противомикробные средства для системного применения

\begin{tabular}{|c|c|c|}
\hline \multirow{2}{*}{ Группа в целом и подгруппы } & \multicolumn{2}{|c|}{ Количество больных, получавших ЛС } \\
\cline { 2 - 3 } & абсолютное количество & 100 \\
\hline Группа в целом & 760 & 100 \\
\hline $\begin{array}{c}\text { в т. ч. Ј 01 (Антибактериальные средства для систе- } \\
\text { много применения) }\end{array}$ & 760 & 4,7 \\
\hline $\begin{array}{c}\text { в т. ч. Ј 02 (Противогрибковые средства для систе- } \\
\text { много применения) }\end{array}$ & 36 & 5,1 \\
\hline $\begin{array}{c}\text { в т. ч. Ј 05 (Противовирусные средства для систем- } \\
\text { ного применения) }\end{array}$ & 39 & \\
\hline
\end{tabular}

Таблица 3

Код R: Средства, действующие на респираторную систему

\begin{tabular}{|c|c|c|}
\hline \multirow{2}{*}{ Группа в целом и подгруппы } & \multicolumn{2}{|c|}{ Количество больных, получавших ЛС } \\
\hline & абсолютное количество & $\%(n=760)$ \\
\hline Группа в целом & 736 & 96,8 \\
\hline $\begin{array}{c}\text { в т. ч. R 01-02 (Средства, применяемые при заболе- } \\
\text { ваниях полости носа и горла) }\end{array}$ & 15 & 2,0 \\
\hline $\begin{array}{c}\text { в т. ч. R } 03 \text { (Средства, применяемые при обструкти- } \\
\text { вных заболеваниях дыхательных путей) }\end{array}$ & 191 & 25,1 \\
\hline $\begin{array}{c}\text { в т. ч. R } 05 \text { (Средства, применяемые при кашле и } \\
\text { простудных заболеваниях) }\end{array}$ & 724 & 95,3 \\
\hline $\begin{array}{c}\text { в т. ч. R06 (Антигистаминные средства для систем- } \\
\text { ного применения) }\end{array}$ & 32 & 4,2 \\
\hline
\end{tabular}


Код В: Средства, влияющие на систему крови и гемопоэз

\begin{tabular}{|c|c|c|}
\hline \multirow{2}{*}{ Группа в целом и подгруппы } & \multicolumn{2}{|c|}{ Количество больных, получавших ЛС } \\
\hline & абсолютное количество, & $\%(n=760)$ \\
\hline Группа в целом & 712 & 93,7 \\
\hline в т. ч. В 01 (Антитромботические средства) & 113 & 14,9 \\
\hline в т. ч. В 02 (Антигеморрагические средства) & 30 & 3,9 \\
\hline в т. ч. В 03 (Антианемические аредства) & 7 & 0,9 \\
\hline $\begin{array}{c}\text { в т. ч. В } 05 \text { (Кровезаменители и перфузионные } \\
\text { растворы) }\end{array}$ & 710 & 93,4 \\
\hline
\end{tabular}

Таблица 5

Код А: Средства, влияющие на пищеварительную систему и метаболизм

\begin{tabular}{|c|c|c|}
\hline \multirow{2}{*}{ Группа в целом и подгруппы } & \multicolumn{2}{|c|}{ Количество больных, получавших ЛС } \\
\cline { 2 - 3 } & абсолютное количество & \% (n=760) \\
\hline Группа в целом & 659 & 56,7 \\
\hline $\begin{array}{c}\text { в т. ч. А 07 (Антидиарейные препараты; средства, } \\
\text { применяемые для лечения инфекционно- } \\
\text { воспалительных заболеваний кишечника) }\end{array}$ & 427 & 8,6 \\
\hline в т. ч. А 11 (Витамины) & 65 & 6,6 \\
\hline в т. ч. А 12 (Минеральные добавки) & 50 & 23,2 \\
\hline $\begin{array}{c}\text { в т. ч. А 16 (Прочие средства, влияющие на пищева- } \\
\text { рительную систему и метаболические процессы) }\end{array}$ & 176 & \\
\hline
\end{tabular}

ную иммунную нагрузку. Нельзя исключить изменчивость состава микрофлоры в этих препаратах. Тем более, что степень дисбиоза кишечника после антибиотикотерапии не исследуется. Поэтому коррекция его «вслепую» пре- и пробиотиками у каждого второго больного, на наш взгляд, может расцениваться как избыточная для саморегулирующейся системы кишечника.

Достаточно широко применяются сульфокамфокаин, биогенные стимуляторы и витамины, однако нет контролируемых клинических исследований, продемонстрировавших достоверно лучшие исходы лечения пневмонии при одновременном их назначении с АБП [5]. Более четких показаний требует и аналогичная ситуация с назначением иммуномодуляторов, так как временный вторичный иммунодефицит обычно не контролируется необходимой лабораторной диагностикой, потому может провоцировать нежелательные реакции. Единственными иммуномодуляторами, рекомендованными для лечения тяжелой НП являются гранулоцитарный колониестимулирующий фактор и $\operatorname{IgG}$ для внутривенного введения [5, 7].

Высокая частота назначений нестероидных противовоспалительных средств противоречит рекомендациям ВО3, согласно которым одновременное их с АБП применение, в силу влияния на течение лихорадки, может извращать оценку адекватного выбора АБП, так как маскирует их неэффективность [5].

\section{Выводы}

1. Анализ антибиотикотерапии негоспитальной пневмонии в стационарных условиях свидетельствует о наличии врачебной полипрагмазии. Такая тактика разрешена в текущих стандартах лечения пневмонии и, наиболее вероятно, продиктована сравнительно сложной клинической ситуацией у тех больных, которые госпитализируются в городские стационары в связи с негоспитальной пневмонией.

2. Коморбидные заболевания приводят к дополнительной фармакотерапии, показания к которой не всегда оцениваются врачами реально и грамотно. Частота назначения препаратов для лечения сердечно-сосудистых заболеваний, органов пищеварения, и в особенности препаратов, влияющих на опорно-двигательный аппарат, превышает частоту, с которой эти заболевания упоминались в сопутствующих диагнозах.

Перспективы дальнейших исследований. Полученные данные могут служить основой планирования комплекса мероприятий по совершенствованию фармакотерапии негоспитальных пневмоний.

\section{Литература}

1. Наказ МО3 України № 128 від 19.03.2007 “Про затвердження клінічних протоколів надання медичної допомоги за спеціальністю "Пульмонологія" - 2007. - Режим доступу: 
http://www.moz.gov.ua/ua/portal/ dn 20070319 128.html

2. Тактика вибору антибіотиків: Навч. посібник / О.О. Яковлева, С.А. Іванова, І.Ф. Семененко [та ін.] / За ред. О.О. Яковлевої. - Вінниця: Нова Книга, 2012. - 224 с.

3. Фещенко Ю.І. Антибіотикорезистентність мікроорганізмів. Стан проблеми та шляхи іï вирішення / Ю.І. Фещенко, М.I. Гуменюк, О.С. Денисов // Укр. хіміотерапевт. ж. 2010. - № 1-2 (23). - С. 4-10.

4. Андреева И.В. Когда следует назначать пробиотики? / И.В. Андреева // Клин. микробиол. и антимикробная химиотерапия. - 2011. T. 13, № 3. - С. 279-282.
5. Внебольничная пневмония у взрослых: практические рекомендации по диагностике, лечению и профилактике / А.Г. Чучалин, А.И. Синопальников, Л.С. Страчунский [и др.] // Клин. микробиол. и антимикробная химиотерапия. - 2006. - Т. 8, № 1. - С. 54-86.

6. Дворецкий Л.И. Внебольничная пневмония: взгляд терапевта [Электронный ресурс] / Л.И. Дворецкий // Consilium Medicum. 2008. - Т. 10, № 3. - Режим доступа к журналу: http://www.consilium-medicum.com/ medicum/article/15664/

7. Синопальников А.И. “Трудная” пневмония / А.И. Синопальников, А.А.Зайцев: Пособие для врачей. - М., 2010. - 55 с.

\section{СТРУКТУРА ПРИЗНАЧЕНЬ ЛІКАРСЬКИХ ЗАСОБІВ ПРИ ЛІКУВАННІ НЕГОСПІТАЛЬНОЇ ПНЕВМОНІЇ В СТАЦІОНАРАХ (ПРОТЯГОМ 2011 РОКУ)}

\section{О.О. Яковлева, Н.В. Щербенюк}

Резюме. 3 метою вивчення реальної практики використання лікарських засобів для лікування негоспітальної пневмонії в стаціонарах м. Вінниці проведений ретроспективний аналіз 760 медичних карт стаціонарних хворих. Результати аналізу показали, що для лікування негоспітальної пневмонії хворі отримували в середньому $10,18 \pm 0,13$ лікарських засобів. Антибактеріальні препарати для системного застосування отримували усі 760 пацієнтів, у середньому, одному хворому їх призначалось $2,51 \pm 0,03$ (від 1 до 7). Досить часто використовувались нестероїдні протизапальні засоби $(38,0$ \%), сульфокамфокаїн $(29,7 \%)$, біогенні стимулятори $(23,2 \%)$, вітаміни $(8,6$ \%). Отримані дані свідчать про поліпрагмазію та можуть слугувати основою планування комплексу заходів щодо удосконалення фармакотерапії негоспітальних пневмоній.

Ключові слова: негоспітальна пневмонія, фармакоепідеміологія, фармакотерапія.

\section{STRUCTURE OF DRUG PRESCRIPTIONS IN THE TREATMENT OF COMMUNITY- ACQUIRED PNEUMONIA IN HOSPITALS (DURING 2012)}

\section{O.A. Yakovleva, N.V. Scherbeniuk}

Abstract. A retrospective analysis of 760 in-patient's medical cards was performed in order to study a real practice of using drugs, when treating community acquired pneumonia in hospitals of Vinnitsa. The results showed that the patients received on the average 10,18 $\pm 0,13$ drugs for the treatment of community-acquired pneumonia. All the 760 patients obtained antibacterial medicines for a systemic use, one patient received on the average $2,51 \pm 0,03$ (1 to 7$)$ of them. Nonsteroidal anti-inflammatory drugs, $(38,0 \%)$, sulphocamphocaine $(29,7 \%)$, biogenic stimulators $(23,2 \%)$, vitamins $(8,6 \%)$ were prescribed quite often. The findings suggest polypragmasia and may serve a basis for planning a set of measures to improve pharmacotherapy of community-acquired pneumonia.

Key words: community-acquired pneumonia, pharmacoepidemiology, pharmacotherapy.

National Pyrohov Memorial Medical University (Vinnytsia)

Рецензент - проф. О.С. Хухліна

Buk. Med. Herald. - 2013. - Vol. 17, № 1 (65). - P. 147-151

Надійшла до редакції 08.01.2013 року

(C) О.А. Яковлева, Н.В. Щербенюк, 2013 